\title{
Transforming gender relations in Nepal's trail bridge programme: policies and practice
}

\section{Mona Sherpa MA, EMBA}

Deputy Country Director, Helvetas Swiss Intercooperation, Lalitpur, Nepal; currently Assistant Country Director, CARE, Lalitpur, Nepal

(corresponding author: mona.sherpa@care.org)

\section{Ansu Tumbahangfe MA, MA}

Results Monitoring and Reporting Manager, Trail Bridge Support Unit (TBSU), Helvetas Swiss Intercooperation, Lalitpur, Nepal

Niraj Acharya MSc, MTechEd

Coordinator, Water and Infrastructure, Helvetas Swiss Intercooperation, Lalitpur, Nepal

\section{Devendra Chhetry PhD}

Former Professor, Department of Statistics, Tribhuvan University, Kathmandu, Nepal

Indu Tuladhar MA

Independent Policy Analyst, Himal Innovative Development and Research Pvt. Ltd., Kathmandu, Nepal

Jane Carter PhD

International Programme Adviser, Helvetas Swiss Intercooperation, Lalitpur, Nepal

This paper considers the extent to which the full and equal rights guaranteed in Nepal's constitution are reflected in the government's trail bridge programme (TBP). A review of the legal provisions and relevant literature was used to inform interviews and field enquiries at nine short-span trail bridges and one long-span bridge. The analysis indicates that the TBP is broadly gender responsive in its policies, but often falls short at field level. Analysis of the findings of the study was guided by five drivers of change for women's economic empowerment identified by the 2016 United Nations High-Level Panel. It considered the degree to which the TBP tackles adverse gender norms and promotes positive role models; addresses unpaid care work; promotes women's assets, representation and leadership; and contributes to a revision of gender-discriminatory laws. The paper concludes with five key suggestions for rendering the TBP more gender transformative: to address the time constraints imposed on women by unpaid care work; to ensure better facilitation of social processes; to strengthen women's leadership; to maximise women's income from wage labour through avoiding debt, turning it into assets and undertaking skills training; to incorporate inclusive community planning and construction of long-span bridges.

\section{Introduction}

\subsection{Basis for the research}

The results of a qualitative research study conducted in late 2016 and early 2017 are presented in this paper. The work was stimulated by the promulgation of Nepal's new constitution in 2015 (GoN, 2015), giving women equal rights as Nepali citizens, and by a reflection on the long experience of Helvetas Swiss Intercooperation in supporting a community approach to trail bridge construction, which seeks to ensure women's strong engagement. The link between inclusive community ownership and good bridge maintenance is well recognised, but the extent to which the full engagement of women community members has been achieved in practice, following recent policy initiatives, needs careful assessment. The aim was to examine the extent to which current laws, policies and guidelines with regard to trail bridges truly reflect the spirit of the new constitution, the agenda of which is essentially gender transformative. In other words, the research team sought to clarify whether existing directives are simply gender aware (recognising existing inequalities between women and men but doing little to change them), gender responsive (adapting to the different circumstances and needs of women and men) or gender transformative (challenging and seeking to change existing inequalities between women and men). The team then considered practice in the trail bridge programme (TBP). This programme is one of the few government programmes that is implemented throughout Nepal. It has been accorded priority 1 status due to the importance that the government has placed on tackling inaccessibility. Inaccessibility is a major constraint in Nepal due to the absence of safe river crossings over more than 6000 rivers and streams. Through the TBP, an average of 450 bridges are completed every year. The majority of these are short-span trail bridges (i.e. with a span of less than $120 \mathrm{~m}$ ) and these bridges were the main focus of this study.

The study sample comprised nine short-span bridges and one long-span bridge (with a span of more than $120 \mathrm{~m}$ ). The focus was restricted to this small number of bridges because the aim was to investigate, in depth, the underlying factors and causes that affect changing gender relations: this also explains the entirely qualitative focus of the research. Nevertheless, the bridges sampled were selected to reflect Nepal's different ecological regions (mountains, hills and southern plains) and entailed interactions with over 100 individuals, including 26 detailed case studies of individual women.

\subsection{The potential of trail bridges for women's economic empowerment}

In the analysis of the ways in which the TBP impacts on gender relations, the team used five of the seven drivers of change for women's economic empowerment identified by the 
United Nations (UN) High-Level Panel (UN, 2016). Thus, the team considered, in turn, the degree to which the TBP

(a) tackles adverse gender norms and promotes positive role models

(b) addresses unpaid care work

(c) promotes women's assets

(d) supports women's representation and leadership

(e) contributes to a revision of gender-discriminatory laws.

The final two drivers of women's economic empowerment as identified by the UN High-Level Panel (UN, 2016) are changed public-sector employment and procurement practices, and changed attitudes in business towards women. Both have relevance for the TBP, but both are also beyond the scope of the programme to change in any fundamental way, at least as it currently stands. The team thus confined observations to the five drivers that can be addressed through the TBP, with four specific areas of action highlighted in Section 5. Prior to this, however, the paper provides details of the methodology, presents some background on gender relations in Nepal within the context of the country's social diversity, discusses the importance of trail bridges to rural transport and sets out the basic features of the government's mandatory community-based approach towards the construction of short-span trail bridges.

\section{Methodology}

\subsection{Research framework}

The primary research involved interviews with a wide range of stakeholders. These took place in district centres in Kathmandu and - most importantly - on site at bridge locations. The interviews were conducted by three groups of the survey team - two groups were women-only while the third comprised both women and men. The survey team was composed of individuals with different expertise and experiences, including a policy analyst, statistician and gender and infrastructure experts; all were individuals with extensive contextual experience. Some interviews were conducted individually and others in focus group discussions (FGDs).

Consultations with key policy makers, policy enforcers and policy advocates in Kathmandu helped to guide the preparation of the questionnaires used at district and field levels. In order to ensure their reliability and validity, they were also pretested at two trail bridge sites - one completed and one under construction.

Nepal's new constitution sets out a federal state structure under which districts will effectively cease to exist. They are being replaced by more decentralised municipalities, governed by elected representatives. As this research was conducted before the federal structure came into effect, consultations took place at district level. Those interviewed at district level included key government officers (staff of the District Technical Officer, the District Development Committee and the Women's
Development Office), staff of non-governmental organisations (NGOs) entrusted with the facilitation of community-based bridge construction, staff of the Trail Bridge Support Programme and private-sector suppliers of bridge components. At local level, interviews conducted with women members of bridge users' committees (UCs), the husbands of such women, female and male labourers employed in bridge construction, bridge wardens and a selection of bridge users. Altogether, 20 FGDs were conducted with trail bridge UC members and beneficiaries (men and women separately, with 8-12 individuals in each FGD).

These FGDs were supplemented by interviews with women at other trail bridges who had specific relevant experience, notably bridge wardens and individuals who had participated in training programmes. As far as possible, the interviewees were selected to include members of both advantaged and disadvantaged social groups. In total, over 100 individual interviews and 26 case studies with individual women were conducted as a complement to the FGDs.

Following collation and preliminary analysis of the data, the research findings were presented to stakeholders at a workshop in Kathmandu. The workshop participants included policy makers, enforcers and advocates, individuals engaged practically in the TBP, and women's rights and development organisations and networks. Those present provided mixed opinions with regard to the extent to which a government TBP can be expected to challenge gender relations.

\subsection{Selection of study sites}

The selection of short-span trail bridges for the study deliberately encompassed all three ecological regions of Nepal; the study sites were thus three in mountainous areas (Darchula district), three in hilly areas (Argakhanchi district) and three in the plains or terai (Morang district) (Figure 1). The long-span trail bridge, in Kaski district, was selected because of its proximity to one of the other sample bridges, in order to facilitate data collection.

Of the short-span trail bridges, six were already constructed and three were under construction. Since the research sought to assess whether the presence of a critical mass of women in UCs affects gender power relations, the bridges were also selected with this variable in mind. Thus, three had UCs with a substantial majority of women members (over 66\%), two had a clear minority (under $30 \%$ women members, although this is not consistent with government guidelines) and the rest fell in between.

\section{Background}

\subsection{Social diversity and gender relations in Nepal}

The last national census of Nepal (CBS, 2012) recognised 125 separate social groups within the population of $26 \cdot 6$ million people. Within this huge diversity, there is a complex social hierarchy based on the Hindu caste system, superimposed onto 


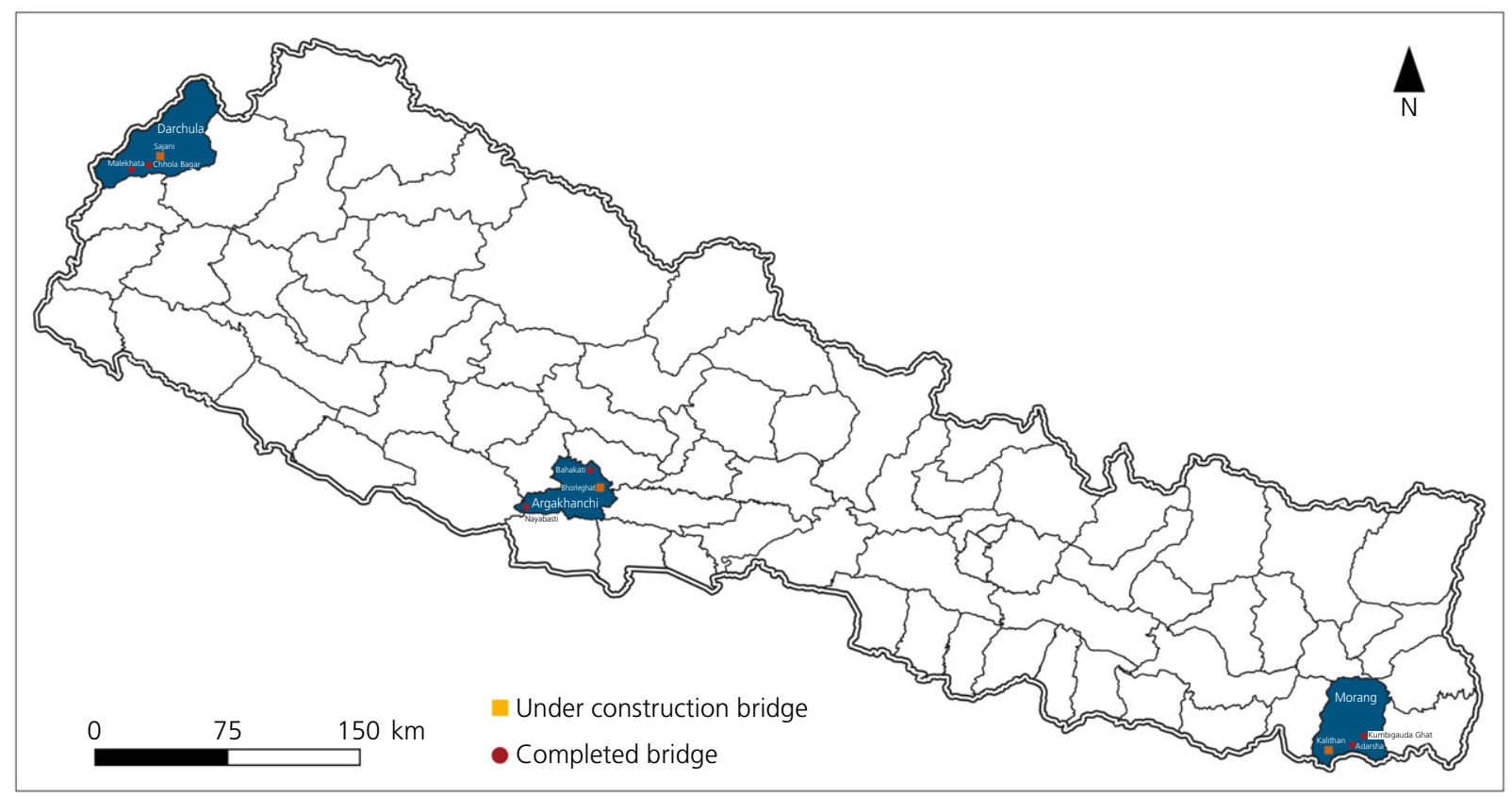

Figure 1. Map of Nepal showing sampled bridge sites

an indigenous population. Broadly, the elites are drawn from four main groups: Brahmins (traditionally the priest caste), Chhetris (traditionally the warrior but also landlord caste), Thakuris (also landlords, mainly based in the west of the country) and the Newars (the indigenous inhabitants of the Kathmandu valley). The most socially marginalised are the occupational castes or Dalits - traditionally smiths, leatherworkers, tailors, musicians, cleaners and similar assigned occupations. In between is a range of indigenous groups or Janajatis, including Sherpa, Tamang, Gurung, Rai, Limbu and Tharu, whose populations tend to be concentrated in different parts of the country. Religion is a further feature of social diversity; Hindus make up the majority of the population (roughly $81 \%$ ) followed by Buddhists (9\%), with smaller numbers of Muslims, animists and Christians.

The caste system was codified in the National Legal Code (Muluki Ain) in 1853 and remained in effect until 1963, when it was abolished by the fourth constitution. Until then, discrimination was legally recognised. For example, Brahmins were exempt from capital punishment, compulsory labour for government public works and certain taxes (Caplan, 1970). The caste-based practice of 'untouchability' was also abolished in 1963. Later, the 1990 constitution upheld the 'existence of plural culture in Nepali society'. This was again reinforced by the 2015 constitution, which, in the preamble, sets out one of its aims as 'Ending all forms of discrimination' (GoN, 2015: p. 12).

Despite these constitutional commitments, caste-based discrimination is still prevalent and entrenched in social, cultural and economic spheres throughout the country (Bhattachan et al., 2003; Dahal, 2002; World Bank, 2006) and remains one of the main reasons for the poorer socio-economic conditions of Dalits and Janajatis compared with other groups. For example, poverty rates are highest among hill Dalits (43.6\%) and terai Dalits (38.1\%) compared with Brahmins (10.3\%) and Newars (10·2\%) (CBS, 2011).

Women also continue to experience widespread discrimination, which is rooted in patriarchy and permeates all spheres of life. Bias in favour of sons means that daughters are discriminated against from birth. Later, as they grow older, they have unequal access to opportunities and consequently lag behind when it comes to educational status, occupational choice and decision making. Furthermore, laws that discriminate against women still exist - particularly those related to nationality and citizenship, property rights and reproductive health (FWLD, 2018).

Discrimination against women is further compounded by caste and ethnic differences. Dalit women are doubly discriminated and tend to have low self-esteem and little belief in their ability to change their lives. In many parts of the country Dalit women are still barred from accessing water from public taps and entering temples due to 'untouchability' practices which, though illegal, are still prevalent (FEDO and IDSN, 2018). In contrast to the often-fatalistic perceptions of Dalit women, Brahmin, Chhetri, Thakuri and Newari women tend to have greater self-confidence and belief in the possibility of selfdetermination within the social construct and legal system of 
Nepal. Janajati women are also regarded as having greater agency and potential for equality compared with Dalit women, with men willing to perform domestic tasks (cooking, cleaning) and share property. However, others also argue that even for Janajati women there are 'many quiet forms of constraint' on their freedom and that their access over various economic and cultural spheres is limited when compared with other castes (Des Chene, 1998: p. 42). Bennett (1983) showed that, due to strong patrilineal structures and myths, Brahmin/ Chhetri women also need to navigate different positions according to their marital status - in her natal home a woman is ritualised and esteemed but in her new home, at marriage, she is an 'outsider' and it is only after giving birth and maturation of her children that she is able gradually to climb to a position of respect.

Presently, to some extent, women's roles are also undergoing a forced change in rural Nepal due to the high prevalence of male migration. On the one hand, the absence of males (primarily husbands) has led to greater autonomy and decision making within households (Hadi, 2001; Kasper, 2006) and has increased women's involvement in the public sphere (Maharjan et al., 2012) but, at the same time, many women are left shouldering the burden of tasks previously performed by men (Maharjan et al., 2012). Studies also indicate that women from migrant households face new forms of moral policing from their communities as they become more engaged in activities outside of their households (Boehm, 2008). Social censure when women enter the labour force was highlighted by GrossmanThompson (2017) in a study of urban women in Nepal. She notes that women are not only in the market economy but also the 'honour economy' - their honour (and that of their families) can be lost if they do not (or even if there is the perception that they do not) conform to social norms. GrossmanThompson also notes that women are constantly subjected to gossip and other forms of gender-based social and sexual violence and, in order to 'insulate' themselves, they employ diverse strategies; however, this constant tension leads to continuous anxieties in their lives. However, Grossman-Thompson further argues that despite the 'tensions', the purchasing power afforded to women through their engagement in the market economy leads many to experience financial freedom, which can also engender a sense of 'personal freedom'.

\subsection{The importance of trail bridges in Nepal}

Trails and trail bridges are not only essential features of rural access in the rugged terrain of Nepal's middle hills and mountains, but also in the plains in the south of the country (the terai) where large rivers can pose major barriers, especially during the monsoon when rivers are in spate. Where there are no trail bridges, whole communities can be cut off from road networks, markets, food supplies, service centres, education institutions and employment opportunities. Although there has been a significant increase in rural road networks over recent years, walking remains the most commonly used form of mobility for the majority of rural Nepalese women, men, girls and boys.

Nepal presently has the highest number of trail bridges in the world. Over 7500 have been built throughout the country, mostly in the middle hills and mountainous regions. The vast majority of these have been constructed with Swiss material and technical support (DoLIDAR, 2017). In addition, the World Bank, the Asian Development Bank and the UK Department for International Development have also provided financing through various projects over the years. The TBP is itself led by the government and guided by the Trail Bridge Strategy (MLD, 2006) and the Trail Bridge Directive (DoLIDAR, 2009). Since 2009, the TBP has been implemented through the government's sector-wide approach. Since promulgation of the new constitution in 2015 (discussed in Section 3.3), local bodies have been given the mandate for trail bridge construction and maintenance. They plan and approve bridges, based on demands received from communities, and are funded either through the federal government's conditional grants or funds generated through their own resources.

On average, a bridge requires a 2-year cycle to be completed (from site selection and design to construction). Once constructed, bridge wardens are appointed and trained by local bodies for routine maintenance.

\subsection{Constitution of Nepal and legal provisions guiding TBP}

The new constitution of Nepal 2015 (GoN, 2015) has several positive elements for women and disadvantaged groups regarding their claim to rights as equal citizens. The preamble clearly commits to '... ending discriminations relating to class, caste, region, language, religion and gender discrimination' (GoN, 2015: p. 12), while Article 38 enshrines the right of women to participate in all state structures and bodies on the principle of proportional inclusion. The statute also states that women must comprise at least $33 \%$ of the members in district coordination committees and $40 \%$ in ward committees to ensure there are women in decision-making roles within local governments. Article 18(4) also clearly prohibits gender discrimination regarding remuneration for equal and same work. Any act of violence against women is also now punishable by law. Directive principles on social justice and inclusion also recognise the economic value of women with regard to child and family care; this is a radical provision - or would be if the mechanisms to enforce the right were also set. In many cases, 'rights' are to be ensured only after the enactment of acts and laws - many of which have yet to be established.

In the case of trail bridge building, the existing policies and strategies, which were established prior to the new constitution, also have yet to be updated. For example, the Local SelfGovernance Act 1999 (GoN, 1999), aims to empower local bodies to formulate plans with the active involvement of and 
participation of local people (including women) and directs representation of women in village and ward level committees to be at least $20 \%$ (which is half of what is already mandated in the constitution). The Local Infrastructure Development Policy (MLD, 2004), seeks to promote a maximum number of women, poor, and disadvantaged groups through employment during construction of infrastructure. Meanwhile, the Trail Bridge Strategy (MLD, 2006), which governs the entire subsector, focuses on ensuring that women's representation in UCs is at least $30 \%$ and that the principle of equal work for equal pay is adopted.

These governing legal frameworks frame women as solely 'targets' or 'beneficiaries'. The Local Infrastructure Development Policy's aim is to increase access of marginalised groups, including women, to social services and economic opportunities. Although the Trail Bridge Strategy targets women in bridge UCs (with at least 30\% representation of women), gender relations and gender norms are largely ignored, especially in recognising that men and women have different opportunities and capabilities to participate and benefit from public programmes.

Later frameworks, such as the trail bridge sector-wide approach framework-II (MFALD, 2014) are, however, more progressive and include affirmative actions, such as the provision of community-leadership training to women with the aim of strengthening their participation in decision making during bridge construction, equal pay for equal work, the targeting of employment (at least 50\% to disadvantaged groups, including women), the requirement of at least $40 \%$ women in UCs (which is already higher than the $33 \%$ quota in the constitution) and at least one individual from a marginalised group in a key decision-making committee.

According to interviews with government and programme officials, the latter quota was introduced to respond to criticisms that UC membership does not necessarily translate into a decision-making role. UCs also need to be proportionately representative of the surrounding population - this is a positive step, as it takes into account the fact that communities are not homogenous units and those who hold power may implement development projects for their own benefit. Nevertheless, it is also too simplified an approach to assume that, by merely reserving positions in UCs, power dynamics that are rooted in historical, cultural and patriarchal structures will be changed. This was evidenced in interviews with Brahmin and Thakuri women in UCs who found difficulties in expressing themselves in front of their elder kinsmen (detailed further in Section 4.4). This shows that the non-project contexts of people's lives (historical, cultural, economic and livelihood-related interlinkages), which impact different spheres, also need to be understood (Cleaver, 1999).

Another major gap is the lack of any clear attempt to minimise the increase in women's workload caused by participation in trail bridge construction. This came out strongly through interviews with women UC members (detailed in Section 4.2.) and is consistent with other studies that have shown that participation in community projects leads to women experiencing significant time poverty as they still have to bear a disproportionate share of household labour obligations (ADB, 2015; Lyon et al., 2016). However, the frameworks and manuals are silent on this matter. Similarly, childcare and sexual misconduct, the latter of which is now punishable as per the constitution, are not even discussed and strategies to address them are consequently missing. These omissions clearly indicate that there is a lot of potential for the TBP to contribute to a revision of the current policies and guidelines.

In addition to the need for revisions, the existing provisions are also only applicable for the 'community approach' for shortspan trail bridges and not to long-span trail bridges built by the private sector. For the latter, the work is solely in the hands of contractors, who have no obligation to target employment opportunities or inform the community about their activities. In the case of the one long-span trail bridge included in this study, this was of particular regret to the users, who had previously worked together on a short-span trail bridge and expected a public hearing to be organised. It seems strange that such hearings are not required as they could also be of benefit to contractors in gaining local support.

Another dimension is that, while gender considerations may be integrated into policies and guidelines, without robust mechanisms, targets and audits, such measures will be limited to just rhetoric (Turner and Spitzner, 2007). Phengkhay (2003) points out that until and unless monitoring measures and performance indicators are well integrated into the implementation of transport policies, integration of gender will become of secondary importance to those that already have indicators to meet (i.e. technical targets).

\subsection{Community-based approach for short-span trail bridges}

Short-span trail bridges, defined as being less than $120 \mathrm{~m}$ in length, constitute some $90 \%$ of all trail bridges in Nepal (DoLIDAR, 2017). Government guidelines require that they are constructed through a community-based approach (MLD, 2006); it is only for reasons of technical complexity that the construction of long-span trail bridges is tendered out to private contractors.

Under the community-based approach, bridge users are organised into user groups, each with a UC. These committees are tasked with the day-to-day management of trail bridge construction, such as arranging the collection of construction materials, mobilising labourers and keeping records of income and expenditure. These UCs must have a minimum of $40 \%$ women and must include members of socially disadvantaged groups (Dalits, Janajatis and minority groups) proportional to their 
representation in the local population (MFALD, 2014). Among the key committee positions (chairperson, treasurer, secretary), one person should be from a discriminated group (e.g. a woman or a person from the Dalits, Janajatis or other minority group). In addition, community leadership training sessions are offered to UC members, especially women, to support their meaningful engagement in decision making. This training is facilitated by staff of the Helvetas Trail Bridge Support Unit (TBSU). With regard to construction work, priority must also be given to local women and members of disadvantaged groups in wage labour opportunities. The principle of equal pay for equal work must be upheld and, following bridge completion, women are prioritised for the position of bridge warden.

While the community-based approach to trail bridge building is overseen by government engineers and technical assistance by Helvetas, the social and technical facilitation is conducted by local NGOs contracted for the task. These NGOs receive $6 \%$ of the total trail bridge cost for facilitation of both technical and social aspects equally ( $3 \%$ each). For social aspects, NGOs need to follow the government's Social Organizational Support Manual (MFALD, 2007) for the implementation of bridges through the 'community approach'. It consists of nine steps and corresponding activities that need to be conducted, from bridge identification to completion and the appointment of bridge wardens.

\subsection{Literature on gendered aspects of transport in Nepal}

The team surveyed the literature on gender issues with regard to transport infrastructure (ADB, 2013; AFDBG, 2009; OECD, 1997, 2004; World Bank, 2010) and it seems to be generally assumed in Nepal that improved transport opportunities whether through trail bridges, rural roads, publicly accessible vehicles or other means - will benefit women and men equally (Sapkota, 2017). However, this is evidently not the case when the relatively limited mobility of women compared with men is considered. Studies in diverse low-income countries have shown that the gendered division of labour and associated time poverty are common barriers reducing the ability of women (and girls) to access essential services (Porter, 2007; Yunusa et al., 2002). Indeed, in some cases women's work burdens increase when men take advantage of improved access to travel to markets and employment opportunities further away from home (Seddon and Shrestha, 2002) and/or when women are left shouldering additional work (collecting fodder) when increased market access leads to rise in dairy demands (Ghimire, 2002).

Information on the utilisation by pedestrians of trail bridges after construction in Nepal, as derived from post-bridgebuilding assessments (PBBAs) (the PBBA distinguishes six key activities: going to school, visiting health services, performing household chores including accessing farmland, going to markets, attending social functions and going to work (employment)), shows clear gender differences between the frequency of, and reasons for, bridge use. Of all bridge users surveyed in 2015, 47\% were women and 53\% were men (Chhetry, 2015). In general, women and girls used trail bridges mostly for going to school, visiting health centres and 'performing household tasks' (such as fodder or fuelwood collection), while men and boys used bridges more commonly for accessing market centres or (paid) work.

According to the PBBAs, the impact of trail bridges on women's health is particularly pronounced. The reports consistently record that more women are seeking treatment from the facilities, especially maternal care. Shrestha (2012) also noted the positive impact of trail bridges on health outcomes. Using figures derived from the Helvetas TBP, she argues that trail bridge construction has contributed to a reduction in maternal mortality through better access to health services, while - in a survey of trail bridge use - $90 \%$ of local respondents considered that there had been an improvement in immunisation campaigns due to more ready access for health staff. However, while the contribution of trail bridge construction to improved health outcomes is obvious to all concerned, direct attribution is difficult, especially given that literature shows that, in addition to access, other factors including the quality of available services, treatment fees and acceptance (by patients to treatments) can also have great significance (Downing and Sethi, 2001; Hartigan, 2001; Thaddeus and Maine, 1994).

With regard to wage-earning opportunities for women and men generated through bridge construction, the team found no analysis in the literature beyond the statistics collected under the trail bridge support information system (TBSIS). This records new employment generated at the bridge sites - an average of 2393 person-days (of which 30\% has gone to women).

Looking at road projects also supported through Swiss assistance, Hada (2012) reports on the positive effect on gender relations achieved through the equal treatment of women and men labourers working on the Lamosangu-Jiri road supported by the Swiss Agency for Development and Cooperation (SDC). She further notes that interventions by the district roads support programme (DRSP) went beyond ensuring fair pay and decent working conditions for the labourers, to include other interventions such as savings and credit schemes. As a result, the women in the road corridors have been significantly empowered. Hada comments further that the benefit of construction of roads using the labour-intensive approach was felt by poor women and men; however, the economic opportunities created from developments following the road construction went mostly to middle-class men who owned businesses.

Starkey et al. (2013) also notes that after the DRSP roads were built, better-off households (with larger landholdings and assets) were more mobile in terms of taking advantage of the 
new opportunities generated. Such lessons have relevance for the TBP, especially as the same donor-funding agency (SDC) is involved in both projects. Nevertheless, there are significant differences in the nature and scale of the two infrastructure programmes, and the employment opportunities during trail bridge construction are generally far fewer than in the roads programme (which is calculated at 98 person-days, on average, for a local labourer (Starkey et al., 2013)).

\section{Findings}

\subsection{Tackling adverse gender norms and promoting positive role models}

The use of trail bridges most stressed by key informants was for schoolchildren - both boys and girls - to reach their classes safely. An average time of $41 \mathrm{~min}$ was reported to be saved for a two-way journey (because of not having to make long detours) (Chhetri and Dulal, 2017). From this perspective, trail bridges may be inferred to have a long-term development benefit that could eventually be gender transformative as studies throughout low-income countries have shown that physical isolation and mobility constraints are important contributing factors to girls' low education achievements (Avotri et al., 1999; Porter, 2007). Furthermore, the PBBAs also consistently record that school attendance for girls (and boys) has risen, by up to $16 \%$ (Chhetri and Dulal, 2017). Furthermore, increased access to education can have far-reaching consequences: it can lead to better job opportunities (World Bank, 2018) and influence fertility rates (Scribner, 1995) and child-rearing practices (Kabeer, 2005).

Another issue worthy of note is the possible contribution of trail bridges in reducing the threat or fear of gender-based violence or harassment. In the absence of trail bridges, due to lengthy travel times through woods, the fear of harassment and violence among women and girls used to be exacerbated, especially while returning from market, schools and health posts. There were hints of this in a number of comments made by women, suggesting they felt safer after the construction of the trail bridges.

Women can now freely walk alone, be it early in the morning or at night. (Brahmin woman, UC general member,

Adarsha bridge, Morang)

Although the research team explicitly enquired about sexual harassment, in the context of provisions to minimise the risk of it at construction sites, replies were inconclusive. As this is not a topic that is readily admitted or discussed, a longer-term investigation would be needed to determine whether or not such incidents are occurring at trail bridge construction sites. Furthermore, the Social Organization Support Manual (MFALD, 2007) is quiet on this matter. Its aim is to ensure active engagement of women and other disadvantaged groups and encourage them to 'speak up' during bridge planning and construction - crucial given the fact that inclusive community ownership is vital for good subsequent bridge management but there are no procedures on how to ensure safe working environments free from sexual misconduct.

The team found clear differences of opinion between various trail bridge UCs, as well as between individual respondents, in the way that gender norms prevailed or had been questioned. Some women seemed simply to accept their passive role and did not see gender-responsive provisions as an opportunity for change. This view is typified in the following comment.

\begin{abstract}
In some cases, women are alone at home as their husbands have gone to India or other countries for work. So they have to look after the children, the elderly, and the cattle. On top of this, they have little education. Thus, women's participation in development activities is low and passive. Men generally take the lead, particularly in construction as this is still considered a man's job. Women members are on the committee and in bridge construction just to fulfil the quota. (Chhetry woman, UC general member, Sajani bridge, Darchula)
\end{abstract}

The team noticed that it was particularly women belonging to Brahmin or Thakuri castes who expressed concern about societal pressure to conform to gender norms; this may arguably be related to a desire to retain caste distinctions that have traditionally given greater prestige and power.

I would like to express myself in the meeting, but when I see other women keeping quiet, I cannot speak up for fear of being accused of being talkative. Most of the men of the committee are my relatives; some are my jetthajoo [jetthajoo are the husband's elder brothers or cousins, with whom interactions are traditionally supposed to be particularly deferential] (Brahmin woman, UC general member, Bhorleghat Bridge, Argakhanchi)

Yet a Dalit woman also expressed a similar concern, in this case possibly alluding to generational differences in perceptions among her male family members.

\footnotetext{
Demanding women's rights creates a rift in the family; to some extent a woman should behave as men expect of her (Dalit woman, UC general member Nayabasti Bridge, Argakhanchi)
}

In other UCs, the research team found references to small ways in which the programme has directly contributed to tackling adverse gender norms and/or promoting positive role models, at least for particular individuals. One positive role model is a Janajati woman, who held the position of treasurer, whose family were particularly supportive. Her comment with regard to her mobility is significant.

There were times when I had to travel to Sandikharka, the district headquarters, for official business with other male members of the user committee and I was apprehensive about how this would be 
viewed by my joint family and in-laws. However, they never complained. (Janajati woman, Treasurer, Nayabasti Bridge, Argakhanchi)

The importance placed on a woman's reputation, which must be free of any possible implication of sexual infidelity, means that many women are either prohibited from travelling with men who are not direct relatives, or themselves fear to do so. Breaking down such suspicions and constraints contributes towards gender transformation; it is therefore important that UC members are encouraged to support women's free movement.

For some women, the opportunity to earn as wage labourers provided a way to take a stand against gendered norms and lead a dignified life, as in the case of another Janajati women, who worked as a labourer.

If I earn then I won't have to be dependent on my husband and he can't tell me what to do. (Janajati woman, labourer, Faklandtapu Bridge, Sunsari)

Overall, the team found that there is potential for the TBP to tackle adverse norms and promote positive role models in a proactive manner and also make use of platforms like UCs to increase awareness. However, to be effective, this requires deliberate and regular facilitation.

\subsection{Reduction and redistribution of women's engagement in unpaid care work}

The heavy burden of work undertaken by, and expected of, women was a constant theme throughout this study. For some, it meant that additional responsibilities associated with the TBP were impossible; for others, it meant that such responsibilities came at the cost of an even greater workload.

\subsubsection{Redistributing unpaid care work}

Those women in the study who were able to participate actively in bridge construction - as labourers or UC members - were generally supported by their families in so doing. Husbands were particularly important in this regard, both in moral support (insisting on their wives' engagement outside the home, sometimes even when other family members were against it) and in practical support by helping with household chores, especially cooking. Indeed, the team gained the sense that some men have realised that positioning their wives in committees is a good way of gaining information about development activities and thus potential benefits. To this end, they are willing to give their support. For example, a Thakuri woman of the Chholabagar UC, Darchula, told the team that her husband took leave from his own work (as a school teacher) to allow her to attend meetings. He himself commented as follows.

Now each and every policy is in favour of women or has provision of the involvement of women. These days there are women

facilitators who encourage other women to take part in development activities, thus increasing involvement of women in the development works. (Thakuri husband of Chholabagar Bridge UC member, Darchula)

For women living in joint families, the redistribution of domestic chores tends to fall to other women or girls in the household - although it was reported that this was willingly done. Nevertheless, one can wonder about the possible opportunities foregone and the additional work borne by those women. Simply shifting tasks to other women is not a real solution - a reduction and redistribution in the work itself is needed and with focused effort more awareness can be generated.

\subsubsection{Reducing unpaid work}

There was some indication from the women's testimonies that trail bridges contribute to reducing the drudgery of unpaid work, particularly by making access to fodder and fuelwood resources and farmlands easier, but also by giving better access to mills for grinding flour, to fields and to shops on the other side of rivers. Coupled with safety, women mentioned time savings of approximately $30 \mathrm{~min}$ for a two-way journey (Chhetry, 2015), making a significant difference to their daily lives, especially for activities that need to be carried out repeatedly.

\subsubsection{Sensitivity to the demands of women's role in unpaid care work}

Sometimes I would get up at 4 a.m. to ensure that I completed all my domestic chores such as cleaning the house, feeding the cattle and cooking food, in order to make it to the user committee meetings. (Brahmin woman, ex-member of user's committee of Kakahare Bridge, Kaski)

Although adjustments in women's other work were made by some families to facilitate the participation of women in UCs, there was little evidence of this being taken into account or accommodated in bridge construction processes. The only exception was with regard to the timing of the UC meetings, which in some cases were deliberately made 'women friendly'. More commonly, however, women complained of meetings being organised with little or no notice, at times that were difficult for them. Indeed, this appeared to be a common way of men sidelining women from decision making. For example, a general UC member belonging to the Thakuri caste claimed that the chairperson and other committee members organised meetings without informing her because she kept insisting on the importance of giving opportunities to local labourers and women. The research team learned that, through employing outside wage labourers at a lower daily rate, the committee members sought to use the money saved to cover the local contribution required for bridge construction. Once again, greater external facilitation and monitoring would appear necessary to uphold due process. 
Interviewees were systematically questioned about provision for childcare, since this was recognised by the research team as an issue that could limit women's participation. The only situation in which this was systematically provided was in training sessions (supported through the TBSU). Provisions to accommodate childcare at construction sites were only mentioned in one case, that of Chholabagar bridge.

Women were given a break from 12.00 p.m. to 2.00 p.m. to cook food and eat, whilst breastfeeding mothers were allowed breaks to attend to their babies. (Dalit woman, UC general member, Chholabagar Bridge, Darchula)

However, this was the exception rather than the rule. It was striking how all concerned - women and men, officials and NGO staff - generally accepted that women labourers would somehow take care of their children regardless and that no provision of support was necessary. The Social Organization Support Manual (MFALD, 2007) is also quiet on the issue, indicating an urgent need for its updating as per the new rights provisioned in the constitution.

\subsection{Increasing women's assets}

Trail bridge construction provides women with opportunities to increase their financial assets in two ways - directly, through wage labour, and indirectly, through improved access to markets and jobs once the bridge is completed.

\subsubsection{Wage labour: equal pay for equal work}

Trail bridge building through the community approach is a labour-intensive process. Construction work is broadly categorised into two categories - skilled (which involves masonry work, stone cutting, bridge part fittings) and unskilled (collecting sand and gravel, preparation of materials for concreting etc.). UCs are responsible for managing labourers during construction by keeping track of the labourers, the number of days of work, the volume of work and payments in a bridge record file, with the support of NGOs. As per the government strategy, they are also responsible for targeting employment for disadvantaged groups (at least 50\%), including women, with priority given to communities within the vicinity of the bridge sites. Other provisions include mandatory insurance for labourers and equal work for equal pay (based on volume of work).

Generally, the construction period is 1 year and on average 2393 person-days of employment are created (MFAGA, 2018). Unlike other community-based public works programmes (such as roads), employment is of a seasonal nature and, depending on the stage of bridge construction, labour needs differ. According to the bridge cost design estimate norms reviewed for this study, employment is highest during concreting of the foundation, when 15-20 labourers are required, and lowest during masonry work on the foundations of the bridge, when six labourers are sufficient.
Within the sampled sites, the team found widespread awareness among officials and local people of the requirement for women and men to be paid equally for equal work.

One example was of Janajati women working at a trail bridge site. Aarati (name changed) had been working at the trail bridge site for 3 months. Like any workplace, men and women work together, but Aarati said there was no discrimination, with the wage paid according to the work of the person. In fact, according to Aarati, men carry heavier loads than women but get paid the same (400 Nepalese rupee (NR) per day (about US\$3.50)). But there were times when Aarati carried heavy loads, even when she was menstruating: 'It was never a problem for me, I never stopped working just because I was menstruating', she said. She is very proud to be earning her own money, especially since her husband is currently working in India, saying 'because I earn money, I don't need to be dependent on my husband and he cannot tell me anything'.

In addition to working Aarati also has to look after two young daughters. But, because her elder daughter is old enough to take care of the younger child she proudly noted 'my elder daughter is a lot of help, she cooks, feeds the younger one, and they go to school. I don't have to worry when I am at work'. But there was a challenge when she was only paid after $14 \mathrm{~d}$ of work. She recalled it made it difficult for her as she had to take loans to meet her daily expenditures.

This story was repeated at all the trail bridge sites. Wages generally followed the local district norms, which vary as they are based on a district's own assessment of market value and not on a national rate. There is also a huge difference between rates for skilled and unskilled labour in all districts (e.g. among the sites sampled, the highest daily rates for both skilled and unskilled labour were in Argakhanchi district at NR 855 (for skilled) and NR 630 (for unskilled) compared with NR 750 (skilled) and NR 535 (unskilled) work in Morang). According to information collected in the FGDs, women are largely employed as unskilled labourers as they lack the necessary abilities for other skilled activities, meaning that women's earning capacity is markedly less than that of most men. Secondary sources indicate that, nationally, the proportion of employment generated for women during bridge construction has remained broadly constant between $25-30 \%$ (see Figure 2). In fact, if the amount actually earned was calculated, it would be even less, given that these figures show days worked and do not differentiate between skilled and unskilled labour.

In a number of the FGDs, women mentioned the importance of wages to pay off loans, mostly for education, but also for buying livestock and farm inputs. However, the team also heard of debts being incurred, at least initially. Payment for community-based construction work is currently made on the 


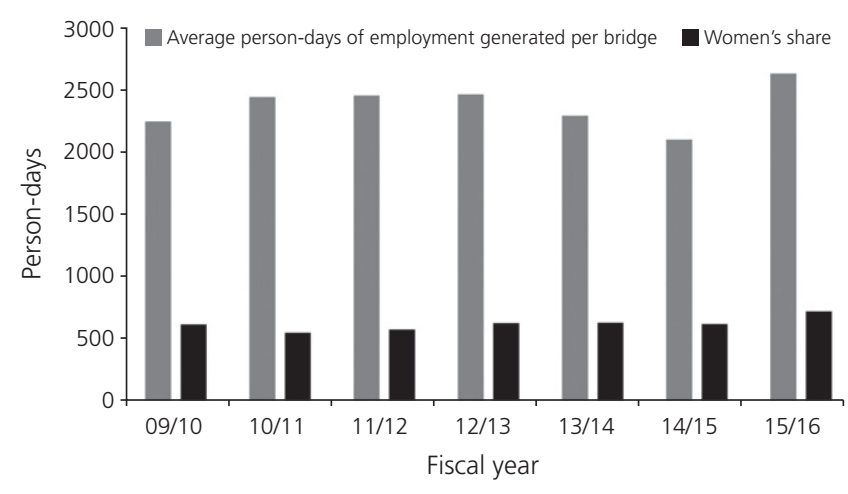

Figure 2. Local employment generated in bridge construction (source: TBSIS)

basis of certified progress. That is, labourers must work for a substantial number of days - normally at least 14 - before they are paid. For those living in quite precarious financial circumstances, especially single women who lack any support from other wage earners, it is not possible to survive this period without a loan and - given local rates of interest - this can constitute a significant reduction in earnings (private money lenders commonly charge $2-3 \%$ per month (i.e. $27-43 \%$ per annum), as per the local rule following a simple interest formula).

In remote areas, the opportunity to earn a regular wage over a substantial period of time (generally at least $40 \mathrm{~d}$ ) has been a novel one for many women, resulting in them having more cash in hand than they are used to, with one woman reporting 'I have never made so much money in my life!' (Dalit woman, labourer, Chholabagar Bridge, Darchula). It was noted that instead of transforming their wages into long-term assets, they used it to fulfil their basic needs before any other investments. For example, asked what they would do with the money that they had earned, two Dalit labourer women (both aged over 50) replied that they would spend it on clothing and food. This is of course their choice, but there is no support available through the bridge-building programme to guide them on other asset-building possibilities. In both cases, wife and husband alike worked as labourers, so there would have been potential to pool family earnings.

Daily life for a Dalit woman labourer during bridge construction was described to the research team as follows.

Sita (name changed) starts her typical day at 5 a.m. After waking up, her responsibilities include cleaning the house, collecting fodder for the livestock and preparing the morning meal. She is assisted in these activities by her sister-in-law and, together, they accomplish most of the tasks by 8 a.m. Getting her son (aged 5 years) ready for school also takes up her morning. By 8.30 a.m. she and her mother- and father-in-law will have eaten their morning meal. After which, she heads down to the bridge site, which is about $15 \mathrm{~min}$ from her house. She has been working as an 'unskilled labourer' at the bridge site for the past 3 months. Her current task is to break large stones using a hammer into smaller pieces (to make construction aggregates), which will later be used in the cement mortar. It is physically demanding and tedious but Sita is grateful to be earning additional cash for her family as her husband has been working in Saudi Arabia for the past 2 years and has not been able to send much cash back home. Which is why, even before the work opportunity at the bridge site, she and her mother-in-law used to make similar construction aggregates to sell in the local market. Now, she notes, her income is more regular. To date, she estimates that she has earned NR 25 000-30 000 (US\$230-300), the majority of which she has already spent on daily household items (such as cooking oil, spices, rice) and on her son's education. At the site, the morning shift usually lasts until 12 p.m., when she and the other workers take their lunch and relax in the shade until 1 p.m. Sita does not have to return home for lunch as meals are prepared at the bridge site (for which she pays NR 50) and her in-laws do not need her to make their afternoon meals. The afternoon shift lasts until 4 p.m., after which she goes back home, just in time to prepare a snack for her son, who will be back from school. By 5.30 p.m. she will have to collect water from the community tap, check on the livestock and start preparing the evening meal. She finishes dinner by 7 p.m. and, after cleaning, keeps an eye on her son as he does his homework, until they go to bed at 8 p.m.

Once trail bridges are complete, there remains a limited opportunity for wage labour as bridge wardens. Appointed by local government bodies, bridge wardens are provided with training and have the responsibility of ensuring that the bridge sites are clean, that nuts and bolts are tightened/or replaced and that side fencing wire is maintained. According to the guidelines, priority for this position, for which an annual amount of NR 6000 (about US\$59) is paid, should be given to women and/or disadvantaged individuals. Although it is considered by government staff to be a desirable position, the (albeit limited number of) interviews that the team undertook led to questioning this assumption, given that it appears to entail a considerable amount of work. The tasks and remuneration of bridge wardens could usefully be reviewed.

\subsubsection{Increased economic opportunities following bridge construction}

I can go to the weekly and other markets on my own, even during heavy rainfall, which I couldn't in the past. (Brahmin woman, UC general member, Adarsha Bridge, Morang)

As noted earlier, information on the utilisation of trail bridges after construction is available from the PBBAs (Chhetry, 2015). Although men represent $58 \%$ of all those going to 
markets, at $42 \%$ there is still a significant proportion of women using trail bridges to buy or sell goods. Relating this to the study sites, business opportunities arising from market access due to trail bridges were indeed mentioned by women at a number of sites, especially Adarsha and Chholabagar. These were mostly due to increased traffic flow of people, where having a small tea-shop was found to be profitable, or at sites where other complementary development activities (such as a hydro-electric plant in Chholabagar) were being constructed.

These days, contractors come to the village to buy vegetables, fruits, honey, goats, and grains. Also with the Chameliya hydro-power scheme on-going, villagers need not be worried about selling their produce, because there will be a ready market. Villagers can now even sell kubindo (wax gourd); no one ever thought this was possible. [In the past, this vegetable was thought to be useless and was either thrown away or fed as fodder to animals.] (Thakuri woman, UC general member, Chholabagar Bridge, Darchula)

PBBA figures also indicate that $32 \%$ of people using the trail bridges to go to work are women. The team also heard of other examples of work or opportunities that became available to women as a result of their experience gained during trail bridge construction. For example, a Janajati woman credited her experience and the confidence gained as treasurer (of Nayabasti bridge UC) as being useful in later applying for and securing the position of secretary in a local agricultural cooperative. A Thakuri woman (general member of Chholabagar bridge UC) also reported becoming a member of the ward citizen forum as a result of her membership of the bridge UC; although not a paid position, she stated that this would give her better insight into and access to ongoing development initiatives. In another case, a Brahmin woman, chairperson of the all-woman Bahakati UC, stated that since the construction of the bridge she has become the chairperson of a 'mothers' group' that concentrates on household savings and creating a revolving fund for low-interest loans.

\subsection{Increased visibility, collective voice and representation of women}

\subsubsection{Positive effects of quotas}

The provision of quotas to ensure the participation of women and disadvantaged individuals in UCs was found to be widely known and respected by officials and local people alike. Some officials seemed unaware that the quota had been recently increased from $33 \%$ to $40 \%$, and should actually be $50 \%$ in order to conform with the constitution, but quotas as a tool were essentially uncontested. Figures show that the average participation of women in trail bridge UCs has steadily risen and currently stands at around $45 \%$ - reflecting the successful implementation of the framework quotas (Figure 3).

The fact that it is mandatory to include at least one individual from a discriminated group, with priority to at least one

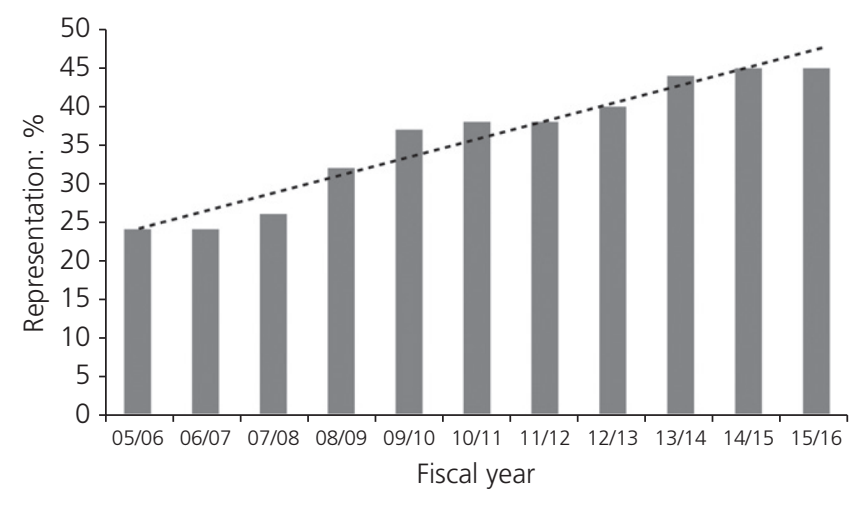

Figure 3. Women's representation in UCS (2005/2006-2015/2016) (source: TBSIS)

woman in an executive position, was appreciated by some respondents - both women and men - as sending a clear message. This is a step towards addressing the current barrier of women's engagement in decision-making positions. It would be beneficial to accompany the quota with initiatives that further consider wider social, cultural and economic dimensions and promote and encourage the meaningful engagement of women like that of a Janajati woman, who held the position of treasurer at Nayabasti UC. She was shy to express her views at first but, with additional support and the encouragement of other members, she gained confidence and became vocal about prioritising labour opportunities for single women during construction.

The traditional view towards women is changing as they are in a key position in any committee. (Janajati woman, UC general member, Adardaha Bridge, Morang)

Nevertheless, the team found evidence of quotas being used by men to place women whom they believed they could manipulate in both executive and general UC positions. This might be done by male relatives or male UC members (sometimes the two being the same). The most blatant example was in the Bhorleghat UC, where a woman was appointed as treasurer but had no wish to take up the position. A fellow woman committee member openly explained how she had been asked, in a conversation outside any official meeting, by the chairperson to join the committee. Furthermore, this invitation seemed linked to her known political affiliations to one of the political parties. Electing women as per policy and procedure is less practised than picking one with close ties (political, family relation or close allies). Many times, this compels women to compromise on the authority given by their position, or to make fair judgements. Such manipulation also leads to patronised relations and allows limited access to other women without such access from the marginalised community, like Dalit women. This keeps leadership in the hands of invisible or hidden individuals, as noticed in the chairperson of Bhorleghat UC. 
On the other hand, leadership opportunities obtained through the quota system have also given women space to practise their leadership, gather experience and build confidence to make decisions. This has also widened their horizons and supported them in building a new identity in Nepali society. Normalcy of women's leadership and its acceptance is greater than before.

Now I can communicate, air my views in a mass meeting, and I am not afraid to travel to the district headquarters alone. My husband and family have changed their perception of me. My husband now says that I can do many things on my own. (Muslim woman, treasurer, Kalsingbridge, Ilam district)

To support women UC members in understanding the bridge construction process and participating fully in meetings, they are offered training in model bridge construction and in leadership skills. However, not all eligible women are able to participate, for reasons that include distance from home or family concerns of sending women alone from their home, as well as other existing commitments on the dates that training is offered. There are also a limited number of seats available for the training (70-80 UC members annually).

A significant finding of this research was that the percentage of women in a UC is not what determines the degree to which women exercise their voices. This is contrary to earlier studies in Nepal, which found that the chance of women attending and speaking at meetings was greater when there were more women in executive committees (Agrawal, 2001). Interestingly, the most positive account of women expressing themselves comes from the trail bridge with the lowest percentage of women in the UC, Nayabasti. In this particular case, one UC member reported that she was always given adequate notice of meetings (allowing her to arrange her domestic chores), that other (male) UC members listened to her views and that she was able to influence decisions - notably in prioritising labour opportunities for single women during construction.

Within the sample of nine trail bridge UCs, two were allwomen committees. This could have been an opportunity for women to exert their collective voice to the full. However, in one (Bahakati), the all-woman composition appeared to have been a way for a local contractor to take full control of the construction process. The women were simply left to ensure the transportation of local materials to the site. In the other case (Ardasha), the women struggled to obtain good-quality construction materials on their own and had to seek help from their male relatives. They were also accused of incompetency and financial mismanagement due to mistakes they made simply through lack of knowledge. This noted, a participant in the male FGD made the following comment.

Women taking the lead was essential because men couldn't commit the time, they had jobs to attend to. Also women are more vigilant and much closer to their homes; this made the task efficient ... If men from the community had formed a users' committee, there would have been an ego clash between them; this is not the case with women. There is trust between women, they intensively monitored [the work] and there was never a case of dispute amongst them. (Brahmin man, Adarsha Bridge user, Morang)

Especially in the light of this observation, which was supported by others, it would be wrong to conclude that allwomen UCs are ineffective. However, they are likely to require particularly good technical facilitation as well as acceptance, support and respect from local men and the community.

\subsubsection{Women as 'a safe pair of hands' in financial matters}

A final point of note in this section is the type of executive position most commonly occupied by women. Figures from 2009-2016 indicate that women are more usually elected as treasurers than other positions, with election to chairperson being particularly uncommon. This seems to reflect a widely voiced belief that women are more trustworthy than men with regard to finances. It may also be linked to the fact that the chairperson and secretary are more commonly expected to travel to district headquarters, which can be difficult for women. At the same time, committees have been known to manipulate members. For example, in Argakhanchi, a shy and illiterate woman who had no wish to take up the position of treasurer was pressured to do so

I was not interested to be the treasurer of the committee, but, the secretary of the committee insisted and I couldn't say no (Janajati Woman, UC general member. Bhorleghat Bridge, Argakhanchi)

Manipulation of the quota system will damage women's leadership and effective participation in UCs if it is not regularly monitored and women's confidence is built. Strengthening of women's agency through building relations with other women members and the wider community to transform practice is also needed. Figure 4 clearly shows women's compromised leadership roles with regards to chairperson and secretary, which are the positions with the largest decisionmaking power within the committee and which have the potential to enable engagement in other community work.

\section{Conclusions}

This research showed that the policy and guidelines for the TBP may be considered gender responsive and socially inclusive but they are in need of updating if inequalities between men and women are to be challenged and changed, especially in light of the new enabling policy environment at the macrolevel promoted by the Nepal's new constitution.

Meanwhile, findings at the micro-level demonstrated the inadequacies of merely having guidelines that are gender responsive, but which are implemented merely to follow 'letter of the law', do not retain the spirit and fall short of expectations. 


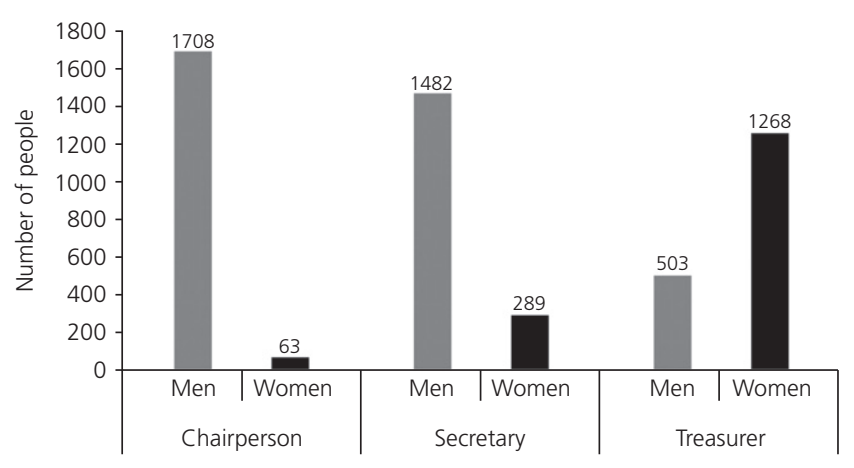

Figure 4. Number of women and men in UC executive positions 2009-2016 (source: TBSIS (completed bridges only))

Unfortunately, some technically oriented stakeholders remain to be convinced that trail bridge construction is an appropriate area for promoting gender equality, although the study team recognises that the technical aspects of bridge construction are important, given that the success of a trail bridge literally stands or falls on technical criteria. It is also evident that the quality of technical implementation is easier to monitor than the quality of social facilitation. Yet Nepal's constitution is clear - all government programmes should uphold equality between women and men, which in effect means promoting a change in current gender relations. At a more prosaic level, the link between inclusive community ownership and good subsequent bridge maintenance is well recognised. The study team thus hopes that the findings of this research - which indicate that progressive policies alone, without efficient, effective and sensitive implementation systems, are not enough for the effort to be gender transformative - will stimulate rethinking. Provisions to translate policies into action are needed, along with improvements in current field practices to render them truly gender responsive and ultimately gender transformative.

There is therefore considerable potential both for revising existing guidelines and, especially, better facilitation and monitoring during implementation. In order to do so, the team suggests five immediate steps that can be made to orientate the TBP in a more gender-responsive, and ultimately gender-transformative, manner. While they are not linked on a one-to-one basis with the five drivers of change addressed in this paper, the suggested steps are drawn from them.

First, the research team gained the impression that it is not always the most appropriate women who become UC members (sometimes deliberately, as a result of manipulation). A number of dynamic, interested women who would probably have made good committee members stated that they had not volunteered due to time constraints. How women's engagement in community decision making can be better supported in practice requires serious thought and process in place, and goes beyond trail bridges, to other aspects of rural development. The team suggests that it should be a matter discussed openly within the community, seeking the suggestions of men and women alike. This would need to be facilitated by NGOs. The provision of childcare facilities for women committee members and labourers is one obvious step, including the provisions in the Social Organization Support Manual (MFALD, 2007), as required by the Labour Act of Nepal (GoN, 2017), but a more general community commitment is needed. For example, the husbands or family members of women selected for committee positions could be required to commit publicly to helping them with domestic chores so that they are able to devote adequate time to the committee without incurring additional work. This could later be followed up by NGO social mobilisers who would encourage the distribution of household chores and childcare to give women more time to engage in UCs. The current quota system is a useful mechanism for ensuring women's engagement in committees and executive positions, although the percentage should be increased to $50 \%$ to be in line with the constitution. Nevertheless, more needs to be done to capacitate women to be active leaders and to orient men to respect them in this role. One way of doing so is to make the leadership training opportunities more widely available. Attending training should be mandatory for UC members. Organising training partly in separate groups for women and men, and partly together, could help break down gender stereotypical attitudes.

Similarly, three means have been identified by which women labourers, many of whom come from disadvantaged groups, could be supported in gaining greater economic benefits during trail bridge construction.

Wage labourers are currently only paid after completion of a given amount of work, with a delay of 2 weeks or more, in contrast to contractors employed to construct long-span bridges who receive a 'mobilisation fee', effectively an advance payment. The team suggests the testing of a similar mechanism for community-based trail bridge construction that would ensure the rapid payment of labourers, if necessary on a daily basis, so that they are not forced to take loans. Additionally, a planned package of skills training to introduce and encourage women in this field and also to break the established stereotype of construction as 'men's work' is required for boosting equal and fair wages for women. Not only that, labourers must be sufficiently empowered to have an informed choice on how they spend their earnings. There are many training programmes available in rural areas on these issues, and an obvious link would be with the Women's Development Office or a local women's rights organisation, which support many such programmes. Another possibility could be to require local NGOs to provide such input specifically to trail bridge labourers.

Discussions with NGO staff revealed that they place far more emphasis on technical issues than social issues, as this is the focus of the current monitoring system. The only social criteria 
in the monitoring system are fulfilment of the UC quotas and completion of the public hearing and public audit. The quality of the social process is not assessed, whereas the quality of technical work is carefully controlled. As a result, there is no incentive for NGOs to check on the power dynamics involved in committee decision making and whether women and disadvantaged groups are truly involved. The limited attention paid to social processes carries on up the line of responsibility, with regional coordinators, district-level development staff and TBSU staff all admitting that this is a weak area. Social facilitation should not only guard against manipulation and other improper practices, but it should also support the active challenge of negative caste, gender and ethnic stereotypes and norms. This needs to be given much more emphasis, with a review of the social monitoring processes and the introduction of better tools.

It is a shortcoming that community consultation is not required of contractors charged with the planning and construction of long-span trail bridges. The team suggests introducing such a requirement - and doing so in a manner that demands equal consultation with women and men, as well as due regard for social inclusion. This would both require private contractors to take social matters seriously, as well as giving local women and men a greater voice in local transport infrastructure. This will also build ownership of the community.

\section{Acknowledgements}

This paper is based on a research project supported by the Research for Community Access Partnership (ReCAP), funded by UK Aid. The research team is grateful to all the members of the community who were involved in the interviews. The team also thanks key informants from the Ministry of Women, Children and Social Works, the National Planning Commission, the Department of Local Infrastructure and Agriculture Roads, the Swiss Agency for Development and Cooperation and District Development Committees and District Technical Offices in the research districts. Special thanks to Paul Starkey for his consistent encouragement during the research and to Gina Porter for her support in finalising this article.

\section{REFERENCES}

ADB (Asian Development Bank) (2013) Gender Tool Kit: Transport, Maximizing the Benefits of Improved Mobility for All. ADB, Mandaluyong, Philippines.

ADB (2015) Balancing the Burden? Desk Review of Women's Time Poverty and Infrastructure in Asia and Pacific. ADB, Mandaluyong, Philippines.

AFDBG (African Development Bank Group) (2009) Checklist for Gender Mainstreaming in the Infrastructure Sector. AFDBG, Abidjan, Ivory Coast.

Agrawal B (2001) Participatory exclusions, community forestry and gender: an analysis for south Asia and a conceptual framework. World Development 29(10): 1623-1648.

Avotri R, Owusu-Darko L, Eghan H and Ocansey S (1999) Gender and Primary Schooling in Ghana. Institute of Development Studies, Brighton, UK.
Bennett L (1983) Dangerous Wives and Sacred Sisters: Social and Symbolic Roles of High-Caste Women in Nepal. Columbia University Press, New York, NY, USA.

Bhattachan KB, Hemchuri K, Gurung YB and Biswakarma C (2003) Existing Practices of Caste-Based Untouchability in Nepal: and Strategy for A Campaign for its Elimination. Action Aid Nepal, Kathmandu, Nepal.

Boehm DA (2008) 'Now I am a man and a woman!' gendered moves and migrations in a transnational Mexican community. Latin American Perspectives 35(1): 16-30.

Caplan L (1970) Land and Social Change in Eastern Nepal: A Hindu Tribal Relationship. University of California Press, Berkeley, CA, USA.

CBS (Central Bureau of Statistics) (2011) Poverty in Nepal 2010/11. CBS, Kathmandu, Nepal.

CBS (2012) National Population and Housing Census 2011. CBS, Kathmandu, Nepal.

Chhetry D (2015) Post Bridge Building Assessment. Trail Bridge Support Unit, Helvetas Swiss Intercooperation, Kathmandu, Nepal.

Chhetri P and Dulal R (2017) Post Bridge Building Assessment. Trail Bridge Support Unit, Helvetas Swiss Intercooperation, Kathmandu, Nepal.

Cleaver F (1999) Paradoxes of participation: questioning participatory approaches to development. Journal of International Development 11(4): 597-612.

Dahal DR (2002) National Dalit Strategy. Action Aid/Care Nepal, Kathmandu, Nepal.

Des Chene M (1998) Fate, domestic authority and women's wills. In Selves in Time and Place: Identities, Experience and History in Nepal (Holland D (ed.)). Rowman \& Little Field, Lanham, MD, USA, pp. 19-50.

DoLIDAR (Department of Local Infrastructure Development and Agriculture Roads) (2009) Trail Bridge Sector Wide Approach Directive 2066. DoLIDAR, Lalitpur, Nepal.

DoLIDAR (2017) District Bridge Records. DoLIDAR, Lalitpur, Nepal.

Downing A and Sethi D (2001) Health Issues in Transport and Implementation for Policy. Department for International Development, London, UK.

FEDO and IDSN (Feminist Dalit Organization and International Dalit Solidarity Network) (2018) Report of Dalit Women of Nepal on CEDAW Convention: Review of Nepal - 71st Session. FEDO, Kathamndu, Nepal and IDSN, Copenhagen, Denmark.

FWLD (Forum for Women, Law and Development) (2018) Committee on the Elimination of Discrimination Against Women: Thematic Submission on Article 9 on Sixth Periodic Report of Nepal on $C E D A W$ 2018. FWLD, Kathmandu, Nepal.

Ghimire G (2002) Transport in the mountains and the terai: Kushiya Damrang and Shivpur, Nepal. In Balancing the Load: Gender, Women and Transport (Fernando P and Porter G (eds)). Zed Books, London, UK, pp. 246-257.

GoN (Government of Nepal) (1999) Local Self-Governance Act. GoN, Kathmandu, Nepal.

GoN (2015) Constitution of Nepal. GoN, Kathmandu, Nepal. GoN (2017) Labour Act. GoN, Kathmandu, Nepal.

Grossman-Thompson B (2017) 'My honor will be erased': working class women, the pleasure of purchasing power and the dangers of modernity in Urban Nepal. Signs: Journal of Women in Culture and Society 42(2): 485-507.

Hada J (2012) Participatory road construction and poverty reduction in Nepal. In Gender, Roads and Mobility in Asia (Kusakabe K (ed.)). Practical Action Publishing, Rugby, UK, pp. 167-174.

Hadi A (2001) International migration and the change of women's position among the left-behind in rural Bangladesh. International Journal of Population Geography 7(1): 53-61. 
Hartigan P (2001) The importance of gender in defining and improving quality of care: some conceptual issues. Health Policy and Planning 16(Suppl. 1): 7-12.

Kabeer N (2005) Gender equality and women's empowerment: a critical analysis of the third millennium development goal. Gender and Development 13(1): 13-24.

Kasper H (2006) 'I am the head of the household now': the impacts of outmigration for labour on gender hierarchies in Nepal. In Gender and Sustainable Development: Case Studies From NCCR North-South (Premchander S and Müller C (eds)). Geographica Bernensia, Bern, Switzerland, vol. 2, pp. 285-303.

Lyon S, Mutersbaugh T and Worthen H (2016) The triple burden: the impact of time poverty on women's participation in coffee producer organizational governance in Mexico. Agriculture and Human Values 34(2): 317-331.

Maharjan A, Bauer S and Knerr B (2012) Do rural women who stay behind benefit from male out-migration? A case study in the hills of Nepal. Gender, Technology and Development 16(1): 95-123, https://doi.org/10.1177/097185241101600105.

MFAGA (Ministry of Federal Affairs and General Administration) (2018) Annual Project Report for Fiscal Year 2075/2076 (2017/2018). MFAGA, Kathmandu, Nepal.

MFALD (Ministry of Federal Affairs and Local Development) (2007) Social Organizational Support Manual, 2nd edn. MFALD, Kathmandu, Nepal.

MFALD (2014) SWAp Framework-II for the Trail Bridge Sub Sector. MFALD, Kathmandu, Nepal.

MLD (Ministry of Local Development) (2004) Local Infrastructrure Development Policy. MLD, Kathmandu, Nepal.

MLD (2006) Trail Bridge Strategy. MLD, Lalitpur, Nepal. See http://www.dolidar.gov.np/wp-content/uploads/2012/09/Trail_ bridge_strategy-2006-English2.pdf. (accessed 12/11/2019)

OECD (Organisation for Economic Co-operation and Development) (1997) Gendernet Practice Notes. Economics and Finance: Infrastructure. OECD, Paris, France. See https://www.oecd.org/dac/genderdevelopment/44843807.pdf (accessed 12/11/2019).

OECD (2004) Why Gender Matters in Infrastructure. Development Assistance Committee Network on Gender Equality, OECD, Paris, France. See https://www.ssatp.org/sites/ssatp/files/ publications/HTML/Gender-RG/Source $\% 20 \%$ 20documents/Issue $\%$ 20 and $\% 20$ Strategy $\% 20$ Papers/G\&T $\% 20$ Rationale/ISGT10 $\% 20$ Why $\% 20$ Gender $\% 20$ matters $\% 20$ in $\% 20$ infrastructure $\% 20$ OECD $\%$ 20DAC\%202004.pdf (accessed 12/11/2019).

Phengkhay C (2003) Integrating Gender Into World Bank Financed Transport Programmes: Case Study Lao People's Democratic Republic: East-West Corridor Project. World Bank, Washington, DC, USA.

Porter G (2007) Transport, (im)mobility and Spatial Poverty Traps: Issues for Rural Women and Girl Children in Sub-Saharan Africa. Overseas Development Institute, London, UK. See https://www. odi.org/sites/odi.org.uk/files/odi-assets/publications-opinionfiles/3536.pdf (accessed 26/04/2019).

Sapkota N (2017) Trail bridges in Nepal: bridges to prosperity. International Journal of Bridge Engineering 5(2): 139-147.

Scribner S (1995) Policies Affecting Fertility and Contraceptive use: an Assessment of 12 sub-Saharan Countries. World Bank, Washington, DC, USA.

Seddon D and Shrestha A (2002) Gender and rural transport development. In Balancing the Load: Gender, Women and Transport (Fernando P and Porter G (eds)). Zed Books, London, UK, pp. 235-245.

Shrestha B (2012) Mobility and accessibility to health services in rural Nepal. In Gender, Roads and Mobility in Asia (Kusakabe K (ed.)) Practical Action Publishing, Rugby, UK, pp. 205-213.

Starkey P, Tumbahangfe A and Sharma S (2013) Building Roads and Improving Livelihoods in Nepal: An External Review of District
Roads Support Programme. Swiss Agency for Development and Cooperation, Kathmandu, Nepal. See http://doc.rero.ch/record/ 255566/files/46-External_Review_District_Roads.pdf (accessed $12 / 11 / 2019)$.

Thaddeus S and Maine D (1994) Too Far to Walk: Maternal Mortality in Context. Center for Communication Programs, Johns Hopkins University, Baltimore, MD, USA.

Turner J and Spitzner M (2007) Reality check: how effective have efforts been to integrate gender into donor agency transport interventions? Transport and Communications Bulletin for Asia and Pacific 76: 35-50.

UN (United Nations) (2016) Leave No One Behind, A Call to Action for Gender Equality and Women's Economic Empowerment, Report of the UN Secretary-General's High-Level Panel on Women's Economic Empowerment. UN, New York, NY, USA. See https://www.empowerwomen.org/-/media/files/un\%20women/ empowerwomen/resources/hlp $\% 20$ briefs/unhlp $\% 20$ full $\% 20$ report. pdf (accessed 12/11/2019).

World Bank (2006) Unequal Citizens: Gender, Caste and Ethnic Exclusion in Nepal. World Bank, Washington, DC, USA.

World Bank (2010) Making Infrastructure Work for Women and Men, A Review of World Bank Infrastructure Projects (1995-2009). World Bank, Washington, DC, USA. See http://siteresources. worldbank.org/EXTSOCIALDEVELOPMENT/Resources/ 244362-1265299949041/6766328-1270752196897/Gender_ Infrastructure2.pdf (accessed 12/11/2019).

World Bank (2018) Missed Opportunities: The High Cost of Not Educating Girls. World Bank, Washington, DC, USA. See https://openknowledge.worldbank.org/handle/10986/29956 (accessed 12/11/2019).

Yunusa M, Shiabu I, Ambi Y, Yusuf A and Abdulkarim B (2002) Road rehabilitation: the impact of transport and accessibility. In Balancing the Load: Gender, Women and Transport (Fernando P and Porter G (eds)). Zed Books, London, UK, pp. 111-118. 